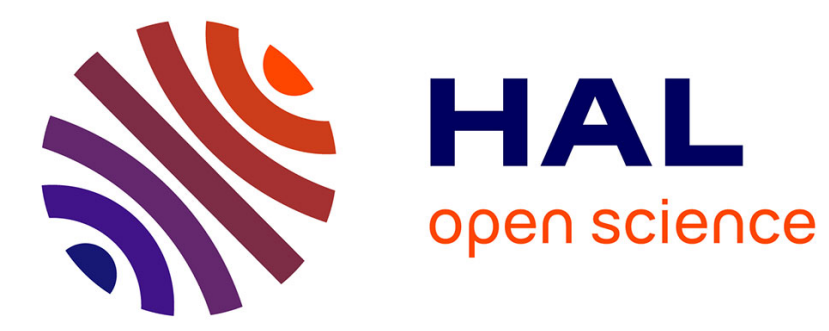

\title{
Bridging in Network Organisations the Case of International Panel on Climate Change (IPCC)
}

Tommaso Venturini, Kari de Pryck, Robert Ackland

\section{To cite this version:}

Tommaso Venturini, Kari de Pryck, Robert Ackland. Bridging in Network Organisations the Case of International Panel on Climate Change (IPCC). 2020. hal-03043546

\author{
HAL Id: hal-03043546 \\ https://hal.science/hal-03043546
}

Preprint submitted on 7 Dec 2020

HAL is a multi-disciplinary open access archive for the deposit and dissemination of scientific research documents, whether they are published or not. The documents may come from teaching and research institutions in France or abroad, or from public or private research centers.
L'archive ouverte pluridisciplinaire HAL, est destinée au dépôt et à la diffusion de documents scientifiques de niveau recherche, publiés ou non, émanant des établissements d'enseignement et de recherche français ou étrangers, des laboratoires publics ou privés. 


\title{
Bridging in Network Organisations the Case of International Panel on Climate Change (IPCC)
}

\author{
Tommaso Venturini ${ }^{1} \quad$ Kari De Pryck $^{2}$ Robert Ackland ${ }^{3}$
}

1. Centre Internet et Société, CNRS, Paris, France

2. CERI Sciences Po Paris, France; Fonds national suisse

3. Australian National University, Canberra, Australia

\begin{abstract}
In this paper, we investigated the relational architecture of the Intergovernmental Panel on Climate Change focussing on the individuals that, in the thirty years of existence of the IPCC, have assured the connection between the different temporal, thematic and functional divisions of the organisation. To identify these bridge individuals, we proposed a new measure of bipartite bridgeness defined as the summation of the inverse Jaccard similarity coefficient of the neighbourhoods of all pairs of divisions to which an individual has participated. As we illustrated using an original database of the eight thousand individuals who contributed to the IPCC since its foundation, this measure of bipartite bridgeness is more informative than the simple degree, as it takes into account the importance and the rareness of the connections assured by each bridge.
\end{abstract}

\section{Introduction}

It is a defining claim of social network analysis (Scott, 1991; White, 1992; Freeman, 2004) and more generally of relational sociology (Tarde, 1893; Emirbayer, 1997; Latour, 2005) that the essence of collective phenomena lies not in external structures but in the internal connections between their parts. This claim is easier to defend when studying dynamics and change, but more difficult when considering continuity and persistence, which, in social sciences, are traditionally associated with macro-structures. The decisive test for relational sociology is therefore to explain the continuity of social organisation and account for the stable empirical regularities that, since Durkheim, represent the bedrock of structural sociology. In contrast to Durkheim's Rules of Sociological Method (1884/1982), we need to ground continuity and persistence not on the "solid foundation" of structures but on "shifting sand" of relations ${ }^{1}$ and show that collective phenomena are in the whole because they are in the parts and not in parts because they are in the whole ${ }^{2}$.

\footnotetext{
1 "Collective habits are expressed in definite forms such as legal or moral rules, popular sayings, or facts of social structure, etc. As these forms exist permanently and do not change with the various applications which are made of them, they constitute a fixed object, a constant standard which is always to hand for the observer, and which leaves no room for subjective impressions or personal observations... In order to proceed methodically we must establish the prime bases of science on a solid foundation, and not on shifting sand." (pp. 82-83, Durkheim, 1884 (1982 translation), emphasis added).

2 "if [a phenomenon] is general it is because it is collective (that is, more or less obligatory); but it is very far from being collective because it is general. It is a condition of the group repeated in individuals because it imposes itself upon them. It is in each part because it is in the whole, but far from being in the whole because it is in the parts." (p. 56, Durkheim, 1884 (1982 translation), emphasis added)).
} 
As an example of this challenge, we propose in this paper to inquire into the peculiar organisation of the Intergovernmental Panel on Climate Change (IPCC). The IPCC is a fascinating institutional puzzle. Despite its gruelling mission - building a consensus on climate change in the academic community and between world governments - the IPCC has prospered as few expert organisations before. While not exempt from criticisms (Lidskog \& Sundqvist, 2015), the IPCC has thrived steadily and under all respects. In its thirty-year existence, the IPCC produced five assessment reports (ARs) whose length has grown from the 1,222 pages of the first assessment report to the 5,021 pages of the last; the number of its authors has quadrupled (from 437 to 1887); the number of national delegates almost tripled (from 590 to 1569). The growth of the IPCC has not only been quantitative. In each successive report, the IPCC has strengthened its authority in the climate debate and consolidated its position at the interface between scientific research and diplomatic negotiations to the point of being awarded the Nobel Prize for Peace in 2007. The IPCC success has also inspired the creation of several other global environmental assessments including the Intergovernmental Science-Policy Platform on Biodiversity and Ecosystem Services (often described as the IPCC for biodiversity).

Remarkably, this expansion has not been accompanied by an institutional hardening. Apart from a secretariat of a dozen members, the IPCC has no permanent organs and no stable employees. All of the eight thousand individuals who contributed to its assessment reports did it on a voluntary basis and on the payroll of other institutions. Unlike other international organisations (Reinalda \&

Verbeek eds., 1998), the IPCC has not entrusted its activities to a group of hired bureaucrats. Instead it has remained a "network-organisation" (cf. Corbera et al., 2015) most of whose contributors are replaced at every assessment cycle and maintain their primary affiliation to other institutions.

The stabilisation of the IPCC in the international climate regime (Hughes, 2015), we contend, is not due to the establishment of hard institutional structures, but to the complex dovetailing of its practice fastened by the relational glue provided by individuals who served in multiple parts of the organisation. We call these individuals "bridges" following IPCC's own terminology, but also because the term resonates with a central theme in social networks analysis. It is known that graph theory itself was initiated by Leonhard Euler (1736) to solve the puzzle of the bridge of the city of Königsberg and since then the notion of bridges between different network regions has received sustained scholarly interest - especially in its application to social phenomena. Jacob Moreno (the father of social network analysis), for instance, dedicated particular attention to identifying the nodes connecting distant regions of his "sociograms" (Moreno, 1934). Yet, it is with the influential paper of Mark Granovetter on The Strengh of Weak Ties (1973) that the importance of social bridges came into full view. Central to the paper is the idea that weak ties are crucial relational assets precisely for their capacity to connect distant social worlds. The same idea is developed by Ronald Burt (2005) who highlights the importance of brokering nodes "connecting across clusters to engage diverse information" (Burt et al. 2013, p. 530). In a different tradition, Luc Boltanski (1973) argued that "multipositionality" - the property of occupying multiple positions in different social fields - is a crucial source of social capital (see also a network analysis of this phenomenon in Venturini et al., 2016) and similar observation has been made about corporate interlocking (Allen, 1974).

In this paper we develop these ideas using the case study of the individual bridging between the different components of the IPCC. Through this analysis, we pursue two objectives. First, we hope to contribute to the understanding of an organisation that is increasingly taken as an example of cooperation between countries and between scientists and policymakers. Second, we propose a new measure of bridgeness in bipartite networks (i.e. two-mode graph that contain two types of nodes and where edges only connect nodes of different types, cf. Borgatti \& Everett, 1997 and Guillaume \& Latapy, 2004). 


\section{The IPCC as a complex organisation}

While bridging is a node-level property that can be measured in any network, we are in this paper particularly interested in bridging in complex organisations - that is, organisations that are composed of subparts which differ in several respects. The IPCC is clearly one such organisation, as its institutional architecture is characterised by a temporal, functional and thematic differentiation.

First, its activities are not carried out as a constant process, but divided in "assessment cycles", each driven by a different leadership and a specific thematic outline. Each assessment is also divided in different phases (definition of the outline, election of the leadership, selection of the authors, writing and reviewing of drafts, distillation of summaries, etc.) and punctuated by yearly or bi-yearly summits, which constitute the only physical meeting between IPCC contributors.

Second, the IPCC is a hybrid organisation, characterised by the cohabitation of scientists coming from different disciplines and diplomats representing different countries. Not only do these two populations often have different professional backgrounds, but they serve different functions in the IPCC: while the authors are tasked with reviewing and summarising climate change literature, the delegates are in charge of managing the process and making sure that the academic outcomes are translated to the policy community (De Pryck, 2021).

Third, IPCC assessment reports are divided into three volumes each produced by a dedicated thematic "Working Group" (WG): WG1 focuses on the physical basis of climate change; WGII on impacts, adaptation and vulnerability and WGIII on mitigation. Because of this specialisation, the working groups tend to be composed of scientists coming from different disciplines, with a prevalence of climatologists in WGI, biologists and demographers in WG2 and economists and engineers in WGIII. Each working group is led by two co-chairs and has access to a dedicated Technical Support Unit. Besides the volumes produced by the three working groups, IPCC reports also contain (from AR2 on) a Synthesis Report (SYR), which combines the results of the three other volumes. Each volume is also composed of different chapters (whose number varies from 7 in AR1-WG2 to 30 of AR5-WG2), but this further thematic subdivision is not considered in this paper.

To investigate the bridges connecting the different components of the IPCC, we collected the names of all the individuals who have contributed to the first five assessment reports of the IPCC ${ }^{3}$. We put great effort to disambiguate homonyms and to merge different names of the same person, but errors may remain. Our database contains about 18,000 rows, each corresponding to a given individual contributing in a given capacity. The 24 capacities we considered are defined by the combination of the temporal, functional and thematic divisions of the IPCC, as illustrated in table 1:

Table 1. Temporal, functional and thematic divisions of the IPCC and the capacities they form

\begin{tabular}{|c|c|c|c|c|c|c|}
\hline \multirow{2}{*}{$\begin{array}{l}\text { Functional } \\
\text { divisions }\end{array}$} & \multirow{3}{*}{$\begin{array}{l}\text { Thematic } \\
\text { divisions }\end{array}$} & \multicolumn{5}{|c|}{ Temporal divisions } \\
\hline & & AR1 & AR2 & AR3 & AR4 & AR5 \\
\hline Delegates & & ar1-delegate & ar2-delegate & ar3-delegate & ar4-delegate & ar5-delegate \\
\hline \multirow{4}{*}{ Authors } & WGI & ar1-author-wg1 & ar2-author-wg1 & ar3-author-wg1 & ar4-author-wg1 & ar5-author-wg1 \\
\hline & WGII & ar1-author-wg2 & ar2-author-wg2 & ar3-author-wg2 & ar4-author-wg2 & ar5-author-wg2 \\
\hline & WGIII & ar1-author-wg3 & ar2-author-wg3 & ar3-author-wg3 & ar4-author-wg3 & ar5-author-wg3 \\
\hline & SYR & I & ar2-author-syr & ar3-author-syr & ar4-author-syr & ar5-author-syr \\
\hline
\end{tabular}

\footnotetext{
${ }^{3}$ The dataset described in this paper has been initiated thanks to the support of the ANR project MEDEA and about half of it completed at the médialab of Sciences Po, through the work of Ian Gray, Nicolas Baya Laffite and Audrey Banneyx, which we greatly thank for their contribution.
} 
Using a tool called Table2Net ${ }^{4}$, we extracted from our database a bipartite network, whose two modes are the capacities presented above (coloured nodes in fig. 1) and the individuals that have contributed to them (grey nodes). The dark grey nodes are our bridges - individuals that connect the different divisions of the IPCC through their varied contributions. The IPCC's procedures

(ipcc.ch/scoping_meeting_ar5/doc10.pdf, p. 10) explicitly identify bridges as those authors who deal "with cross-cutting topics across WGs" in the same AR. Beside these thematic bridges, we extended the IPCC's definition to consider also functional bridges, individuals who have served as both author and delegate in the same AR; and temporal bridges, individuals that have participated in more than one AR while having the same function within the same $W G$ (the SYR being considered as a WG for the purpose of this paper).

For reasons that we will explain in the next section, we do not consider mixed bridges, i.e. individuals that have participated in different ARs in different functions or different WGs. According to this definition, our network contains 1,198 bridges, amounting to more than one fifth of the total of 5,676 contributors in our dataset ${ }^{5}$. Edges are weighted according to the number of times that each individual has served in the same capacity (for example, authoring two different chapters within the same WG report during the same AR).

Figure 1. Bipartite network of the IPCC contributors and the capacities in which they have served (capacities are coloured according to their functional and thematic division; bridges are dark grey nodes)

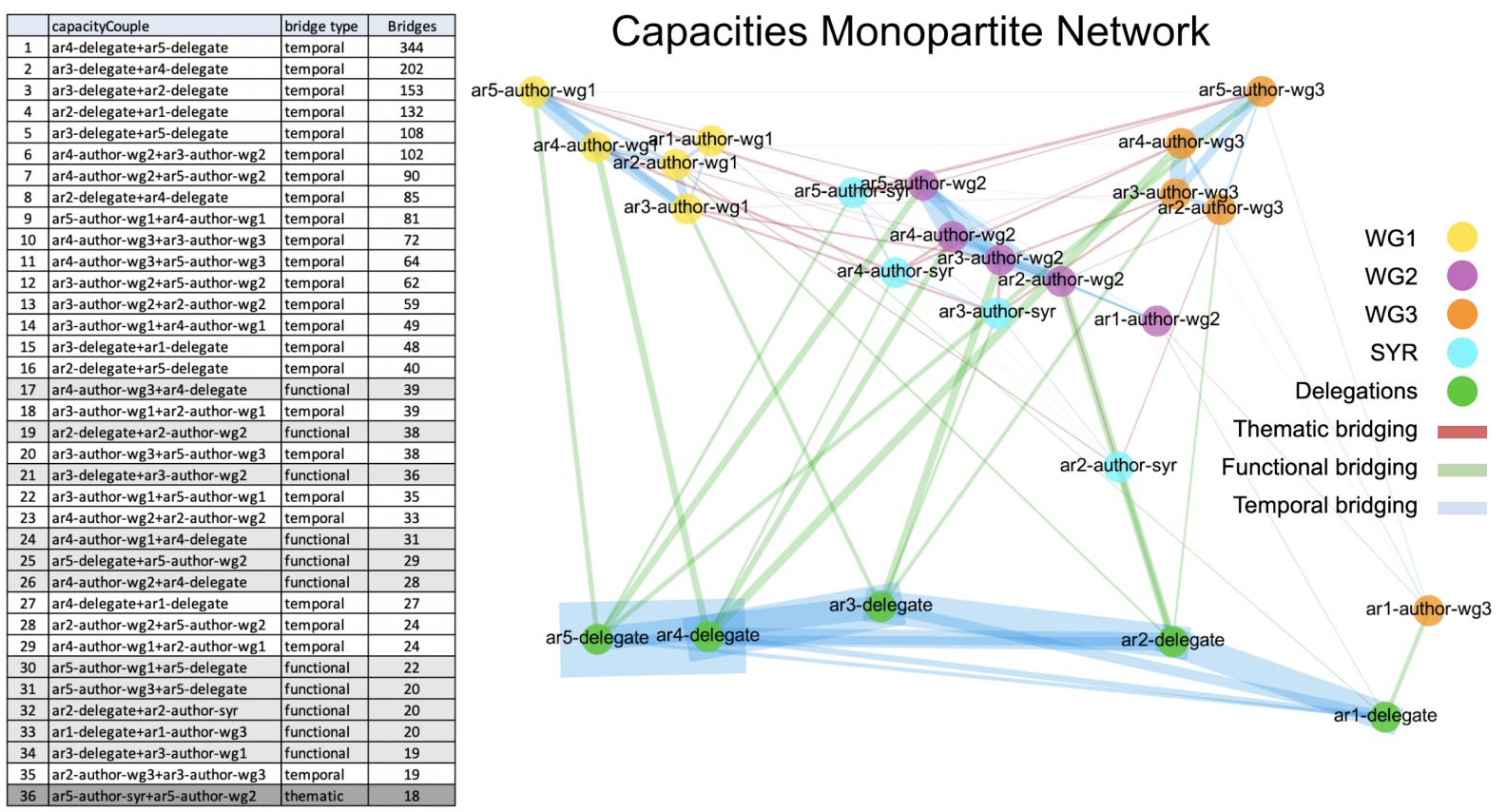

Before moving to the mathematical analysis, a visual inspection of the network above yields some interesting insights. The network in fig. 1 has been spatialised with a force directed layout (Jacomy et al., 2014), which draws closer the nodes with more direct (and indirect) connections between them, and pushes away nodes that are less connected to one another. This means that spatial proximity is a

${ }^{4}$ http://tools.medialab.sciences-po.fr/table2net/

${ }^{5}$ It is important to note that our network only includes Contributing Leading Authors, Leading Authors or Reviewers (i.e. only the authors with roles of coordination and responsibility and who are directed selected by the IPCC Bureau). We have not considered Contributing Authors (who are invited to submit written contributions to specific paragraphs in the reports chapters) because, while their contribution is scientifically important, the fact that they do not participate in the author meetings of the IPCC diminishes their importance as organisational bridges. The edges of the graph represent the contribution of each individual. 
good indicator of structural grouping (Venturini et al., 2020). The clustering in the figure appears to reflect above all the functional division of the IPCC (with authors and delegates located respectively in the upper and lower part of the network), but also the thematic division (with a clear separation between the three $\mathrm{WGs}^{6}$ ). We coloured the nodes according to these divisions precisely to highlight the fact that they do not mix in the figure. It is interesting that the only mixing concerns the capacity "ar1-author-wg3", which is positioned very close to the delegates cluster. This offers a confirmation of our method, because in the first assessment cycle, the WG3 was mandated with the highly politicised task of formulating response strategies to climate change and involved many government officials and negotiators (Skodvin, 2000).

It is also interesting to notice the middle position occupied by the SYR of AR2, which is distinctively closer to the delegates than the other Synthesis Reports, this can be explained by the fact that in its first edition (the SYR being introduced in AR2), the Synthesis Report was authored mostly by members of IPCC Bureau many of whom were also part of their national delegation.

In contrast to the high functional and thematic clustering, the temporal articulations of the IPCC in different ARs does not seem to produce much clustering, as nodes of the same AR are generally far one from another ${ }^{7}$. This means that there are more bridges between the same functions or themes in different ARs, than between different functions or themes in the same AR. The prevalence of temporal bridging is even more evident if we transform our bipartite graph into a monopartite one in which the different capacities are connected by edges weighted by the number of individuals that they have in common. In figure 2, the edges between different pairs of capacities are sized according to their weight and coloured by their type. The temporal bridge edges (blue) are significantly thicker (reflecting the fact that more individuals are fulfilling this type of bridging), compared with the functional bridge edges (green) and thematic bridge edges (red).

Table 2. Most intensely bridged capacity pairs
Figure 2. Monopartite graph of IPCC capacities. Edges are coloured by type of bridging and weighted by the number of common contributors.
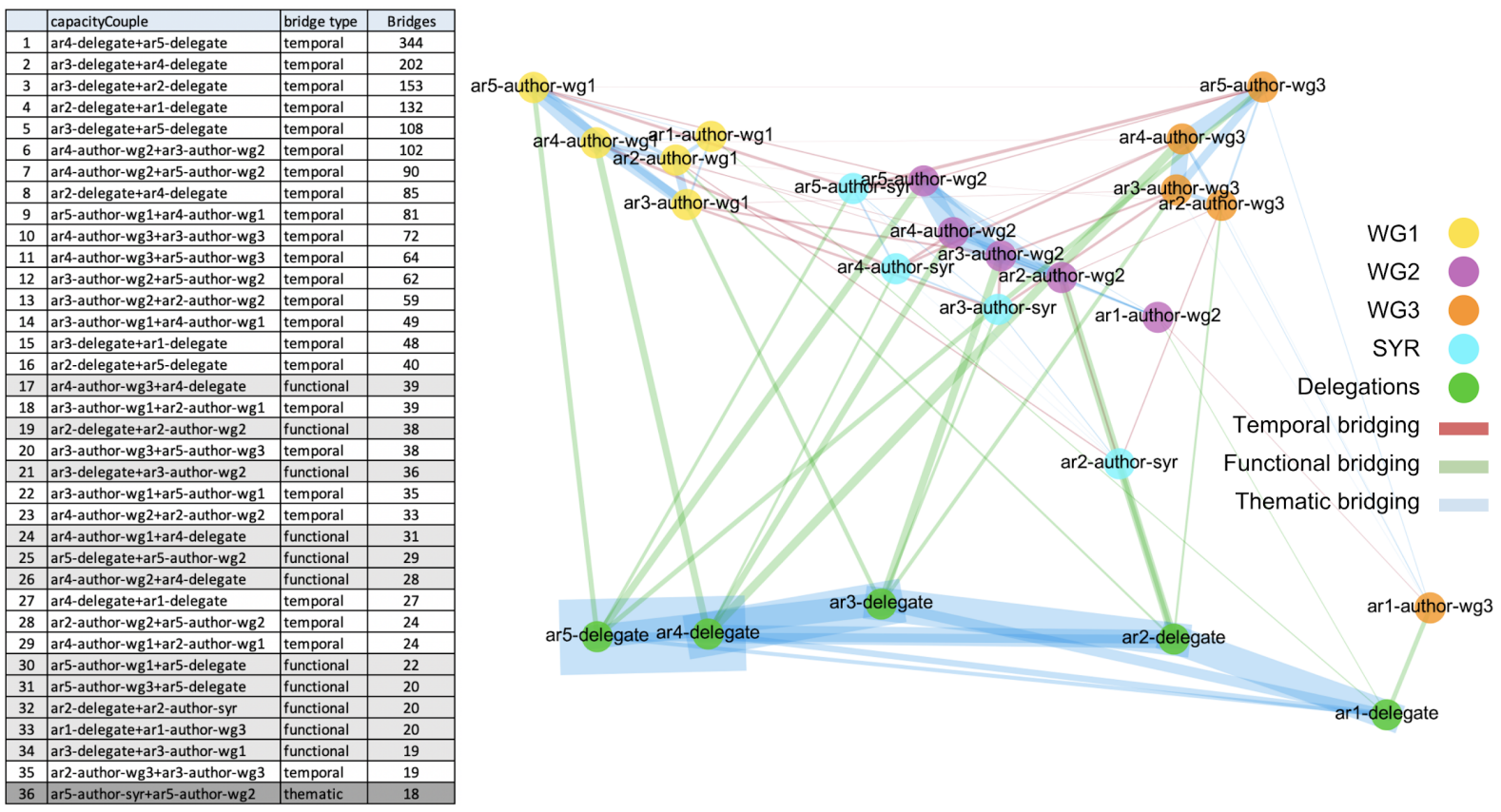

${ }^{6}$ As expected, the SYR authors are consistently positioned between the three working groups, reflecting their role in providing a synthesis of the working groups.

${ }^{7}$ Note however that in each WG cluster and in the cluster of delegates, the ARs tend to be ordered chronologically from right to left, which indicates that more bridges exist between temporally adjacent ARs. 
This prevalence of temporal bridging is also confirmed by looking at the composition of bridging individuals. Our dataset contains 1088 temporal bridges (individuals who have participated in the same function - delegate or author - in two or more ARs, compared with only 255 functional bridges (individuals who participated as both delegate and author in the same AR) and 143 thematic bridges (individuals who participated as authors in two or more WGs in the same AR) ${ }^{8}$. The first finding of our analysis is therefore that the one type of bridging explicitly acknowledged in IPCC procedures, the thematic one, is by far the least common in our dataset ${ }^{9}$.

\section{A measure of bipartite bridgeness}

Having examined how the IPCC capacities are connected to one another through bridging individuals, we can move to consider the other 'mode' of our bipartite network, that is to say the individual contributors. The objective here is to identify which individuals are most important in bridging the different divisions of the complex organisation that is the IPCC. Using the classic measure of betweenness centrality (Freeman, 1977; Brandes, 2001) is not fully satisfying here, because this solution does not take into consideration the "bipartite" nature of our graph. Drawing on the fact that, in bipartite networks, nodes of the same type are never directly connected, we propose to measure the bridgeness of a node as a function of the inferred or imputed connections that it creates among the nodes of the other type. The simplest way to implement this idea is to define the bipartite bridgeness of a node $\alpha$ of type $A$ as the number of pairs of nodes of type $B$ nodes that have inferred connections due to the linking activity of $\alpha$. This number is the equal to the number of unique combinations of unordered pairs of $\alpha$ 's neighbours, and is therefore directly related to the degree of $\alpha$ :

$$
\text { pairs of nodes bridged by } \alpha=\frac{\operatorname{degree}(\alpha) !}{2 ! *(\operatorname{degree}(\alpha)-2) !}
$$

This measure, however, considers each act of bridging as equivalent and discounts the fact that different B-nodes can have different importance as well as the fact that some inferred connections between B-nodes will be more uncommon than others. To take these two elements into consideration, we propose an alternative definition of the bipartite bridgeness of a node $\alpha$ of type $A$ as the number of pairs of nodes of partition $B$ that it bridges, weighted by: (1) the total number of neighbours of the two bridged B-nodes and (2) the inverse of the number of A-nodes bridging the same pair. In other words, we define the bipartite bridgeness of $\alpha$ as the summation for each pair i, j bridged by $\alpha$ of the size of the union of their neighbours divided by the size of the intersection of their neighbours.

$$
\begin{aligned}
B B(n)=\sum_{i, j} & \frac{\mid \text { neighbours }(i) \cup \text { neighbours }(j) \mid}{\mid \text { neighbours }(i) \cap \text { neighbours }(j) \mid} \\
& =\sum_{i, j} \frac{1}{\operatorname{Jaccard}(\text { neighbours }(i), \operatorname{neighbours}(j))}
\end{aligned}
$$

\footnotetext{
${ }^{8}$ Note that the sum of these different types of bridges is greater than the total number of bridges $(1,198)$ because the same individual can bridge the organisation in different ways. In fact, the prevalence of temporal bridging is also indicated by the fact that most of the functional and thematic bridges are also temporal bridges (only 81 and 34 , respectively, are not) while most temporal bridges (861) are only temporal.

${ }^{9}$ This finding depends, at least in part, on the fact that our definition of bridging is very strict and only takes into consideration authoring contributions in coordinating or reviewing roles. Accordingly, in this study, thematic bridges tend to be scientists with significant expertise in two or more disciplinary sectors, which is by definition very rare. A more common (but weaker) way of connecting two WGs is to participate as coordinating or reviewing author in one group and only as contributing author in the other.
} 
The size of the intersection of two sets divided by the size of their union is commonly known as the Jaccard coefficient of those two sets, and hence bipartite bridgeness can be defined as the summation of the inverse Jaccard similarity coefficient of the neighbourhoods of all pairs of neighbours of $\alpha$. The fact that the Jaccard similarity coefficient is a classic measure of similarity between sets provides intuitive support for our bipartite bridgeness measure since we want to capture not only the number of pairs bridged by the node $\alpha$, but also their relational diversity ${ }^{10}$.

In figure 3 below, the node ' $\varepsilon$ ' has a bridgeness of 7, which comes from being the only bridge between ' $a$ ' and ' $b$ ' (size of union is 2 , size of intersection is 1 ) and between ' $a$ ' and 'c' (size of union is 3 , size of intersection is 1 ). $\varepsilon$ also bridges the pair ' $b$ ' and ' $c$ ' (size of union is 4 , size of intersection is 2 ) but shares this bridging with another node (hence the division by 2 ).

Figure 3. Simple examples of calculation of bipartite bridgeness.

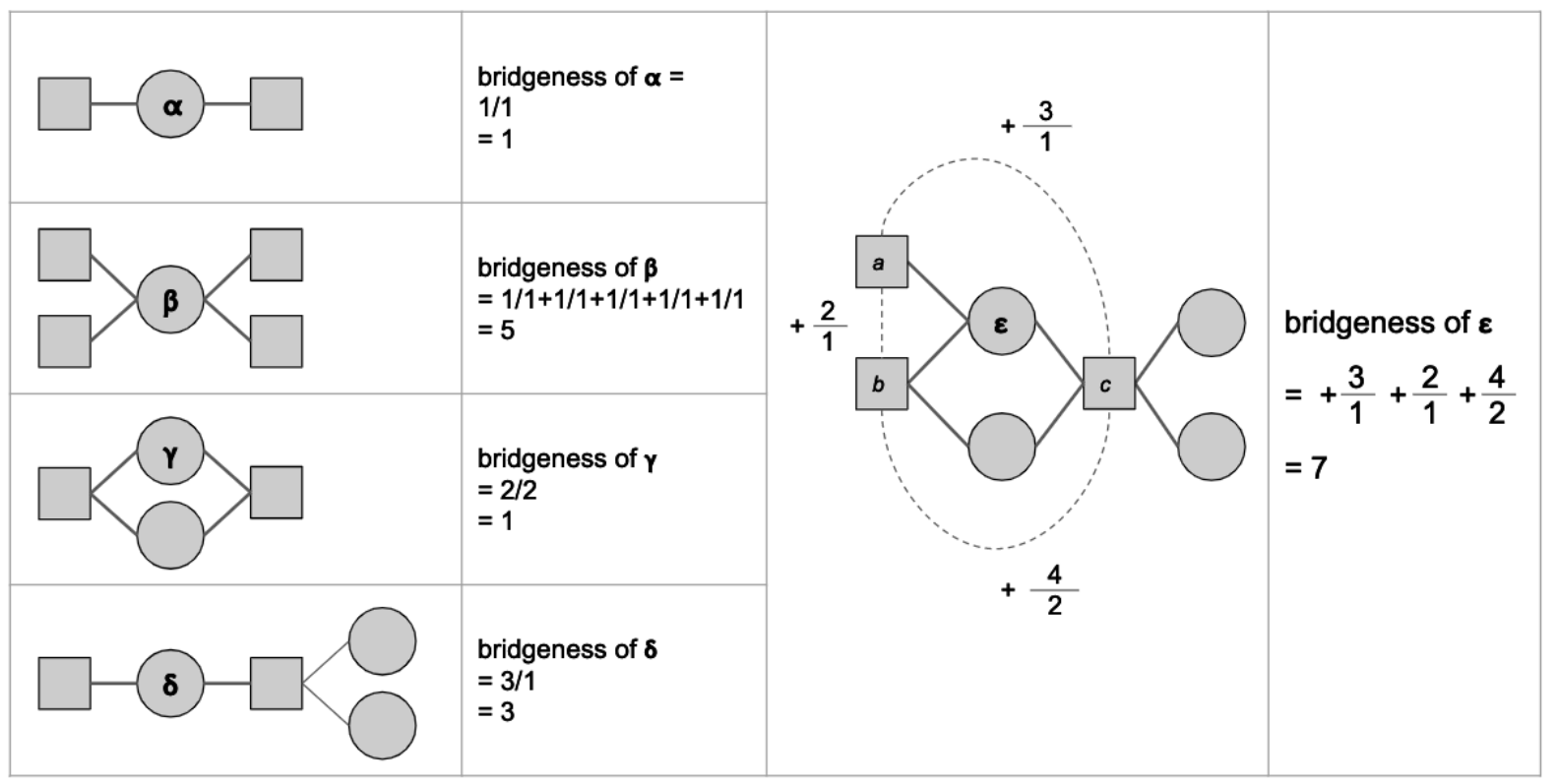

In our IPCC network, the bipartite bridgeness of each individual is then the summation, for each pair of capacities bridged by that individual, of the total number of the individuals who served in either of the two capacities (i.e. the size of the union of the capacities' neighbourhood in the bipartite network) divided by the number of individual who served in both (i.e. the size of the intersection of their neighbourhood). Being defined as a summation over the pairs of capacities bridged by an individual, our measure is strongly correlated to the degree of the individual in the bipartite network. Yet, because it also takes into consideration the total number of individuals participating in the two capacities (in its numerator) and the rarity of overlaps of individuals i.e. their bridges (in its denominator), it offers a more nuanced way of identifying the individuals occupying key bridging positions in our complex organisation.

\footnotetext{
${ }^{10}$ Note that our measure of bipartite bridgeness is also a direct implementation of the idea of "weak ties" imagined by Granovetter in the article cited in the introduction of this paper:

Consider, now, any two arbitrarily selected individuals-call them A and B-and the set, $\mathrm{S}=\mathrm{C}, \mathrm{D}, \mathrm{E}$, $\ldots$, of all persons with ties to either or both of them. The hypothesis which enables us to relate dyadic ties to larger structures is: the stronger the tie between A and B, the larger the proportion of individuals in $\mathrm{S}$ to whom they will both be tied, that is, connected by a weak or strong tie. This overlap in their friendship circles is predicted to be least when their tie is absent, most when it is strong, and intermediate when it is weak. (Granovetter, 1973, p. 1362).
} 


\section{Discussion and results}

Quantitative evidence of the analytical value of our measure comes from the comparison with another piece of information which we have not yet considered. In table 1, we purposely omitted another crucial role in the IPCC: that of Bureau members. The Bureau supervises the work of the IPCC and its members are selected by the Member states at the beginning of each evaluation cycle.

Because we did not include the information about Bureau membership in our network, we can now use this information to validate our measure of bipartite bridgeness. Because Bureau members are officially in charge of coordinating the work of the IPCC, we expect them to have a higher bridging score than other IPCC members because first, their election is facilitated by a long and varied engagement with the organisation and second, because their role necessitates their involvement in different divisions of the organisation. Indeed, we find that the proportion of Bureau members that are also bridges (in the sense that they have a bridging score higher than zero) is much higher than the proportion of non-Bureau members: $84 \%$ against $20 \%$. Even by focussing exclusively on the subpopulation of Bureau members and non-Bureau members that are bridges, both the mean and the median of bipartite bridgeness is considerably higher for Bureau (mean- $\mathrm{BB}=1717$ and median- $\mathrm{BB}=$ 1139) than for non-Bureau (mean-BB $=357$ and median- $B B=96$ ).

It is also possible to use the information about Bureau membership as evidence that our measure is more informative than the simple measure of degree in the bipartite network. Indeed, Bureau members generally rank higher when IPCC contributors are sorted by bipartite bridgeness, than when they are sorted by degree. The average ranking for Bureau members is 729 when ranked by bipartite bridgeness and 880 when ranked by degree (and 220 against 297 when only contributors with a bridging score higher than zero are considered).

Another, more qualitative, way of comparing bipartite bridgeness with degree comes from identifying the most important actors by each measure. Figure 4 displays the top- 54 contributors by bridgeness (bridgeness $>1080$ ) and by degree (degree $>5$ ) in a bridgeness VS degree scatterplot.

Figure 4. Scatterplot of the top-54 contributors by degree and by bipartite bridgeness. Bureau members are colored in red.

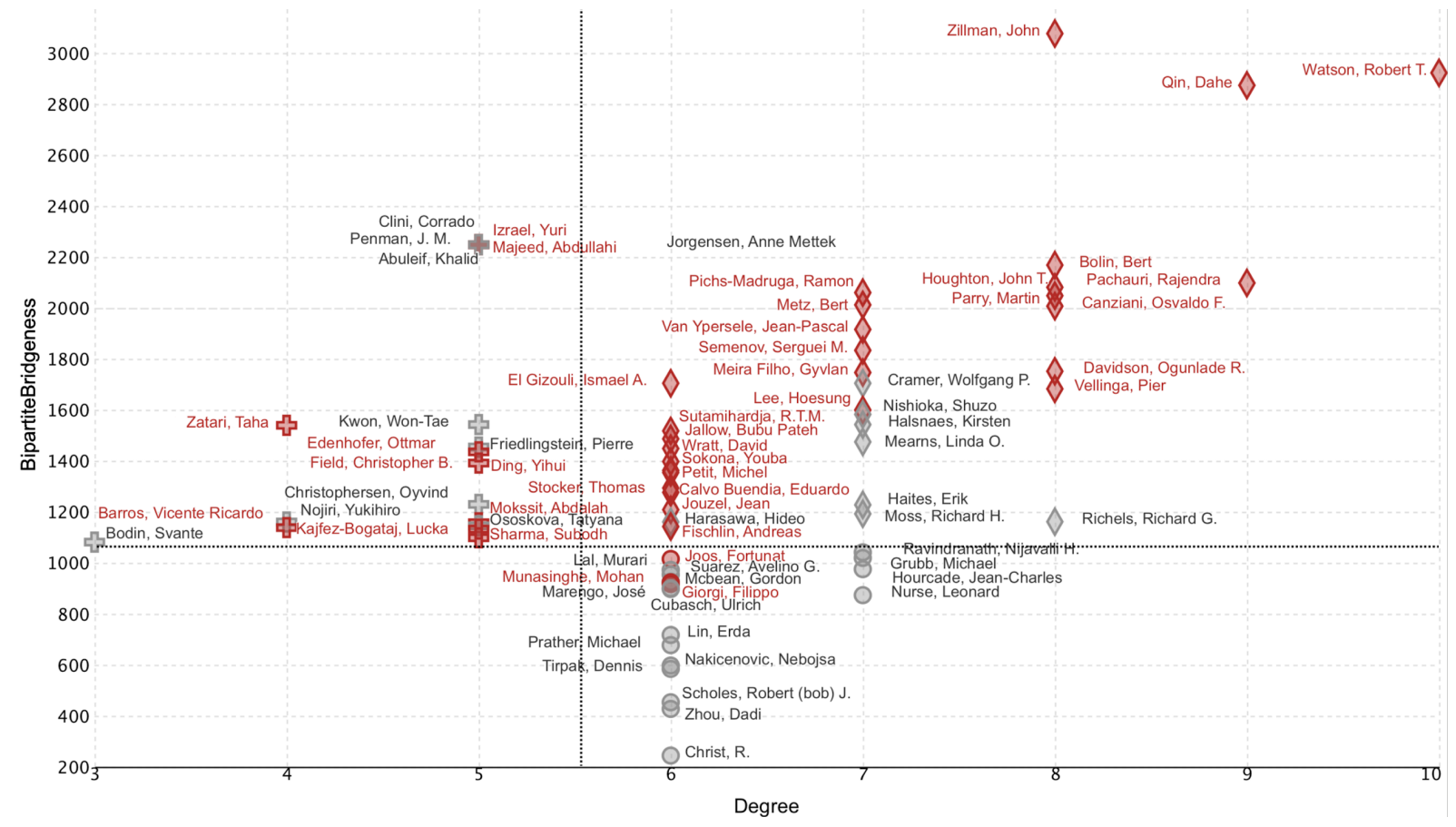


In the quadrant that contains contributors that are top-ranked only according to bridgeness (top-left), we find people who played crucial roles in the IPCC and that would have not been highlighted by degree alone. For instance, we would miss Taha Zatari and Yuri Izrael, who, despite having a degree of only 4 and 5 respectively, have been highly influential contributors to the IPCC as Bureau members and long-standing members of their delegation (respectively Saudi Arabia and the Russian Federation).

So far, we have worked with a general definition of bridgeness that does not discriminate between the three different types of bridging discussed above. It is however not difficult to decompose such general measure into its thematic, functional and temporal components. Table 3 below displays the top- 25 bridges by types of bridging.

Table 3. Top-20 bridges for each type of bridgeness. Bureau members are in bold and contributors present in more than one ranking are highlighted in grey.

\begin{tabular}{|l|l|l|}
\hline Top-20 thematic bridges & Top-20 functional bridges & Top-20 temporal bridges \\
\hline Mearns, Linda O. & Qin, Dahe I Qinh, Dahe & Zillman, John \\
\hline Grubb, Michael & Watson, Robert T. & Abuleif, Khalid \\
\hline Watson, Robert T. & Pachauri, Rajendra & Clini, Corrado \\
\hline Toth, Ferenc L. & Pichs-Madruga, Ramon & Izrael, Yuri \\
\hline Bolin, Bert & Canziani, Osvaldo F. & Jorgensen, Anne Mettek \\
\hline Richels, Richard G. & Davidson, Ogunlade R. & Majeed, Abdullahi \\
\hline Kheshgi, Haroon S. & Van Ypersele, Jean-Pascal & Penman, J. M. \\
\hline Patt, Anthony & El Gizouli, Ismael A. & Zatari, Taha \\
\hline Karoly, David J. & Edenhofer, Ottmar & Semenov, Serguei M. \\
\hline Robinson, John B. & Friedlingstein, Pierre & Bodin, Svante \\
\hline Marengo, José & Field, Christopher B. & Parry, Martin \\
\hline Mcfarland, Mack & Parry, Martin & Cubasch, Ulrich \\
\hline Christensen, John M. & Houghton, John T. & Miotke, J. A. \\
\hline Barry, Roger G. & Sokona, Youba & Teuatabo, N. \\
\hline Prather, Michael & Metz, Bert & Watson, Robert T. \\
\hline Vellinga, Pier & Cramer, Wolfgang P. & Nishioka, Shuzo \\
\hline Davidson, Ogunlade R. & Kwon, Won-Tae & Ding, Yihui \\
\hline Kwon, Won-Tae & Nishioka, Shuzo & Houghton, John T. \\
\hline Nojiri, Yukihiro & Lee, Hoesung & Lee, Hoesung \\
\hline Pachauri, Rajendra & Stocker, Thomas F. & Vellinga, Pier \\
\hline
\end{tabular}

The diversity of the three types of bridging is illustrated in the table by the fact that most contributors are only present in one ranking (the white background cells). Among the contributors that feature as top bridges according to different types of bridging, we found for example Linda Mearns (senior climate scientists at the US National Center for Atmospheric Research) who has bridged between WG1 and WG2 in three following cycles, AR3, AR4 and AR5 (and is also active in the current AR6) and Michael Grubb (Professor of Energy and Climate Change at University College London), who has bridged WG1 and WG3 in AR2 as well as WG2 and WG3 in AR4. Looking at the table, we can also observe that Bureau members tend to be higher ranked as functional bridges than as thematic or temporal bridges. This is not surprising as, in order to be elected as Bureau members, contributors need to have credible scientific credentials but close ties with the national delegation that nominates them. 
Another way of making similar observations is projecting the values of our bipartite bridgeness on the network of figure 1, by varying the size of the nodes representing the contributors according to their bridgeness score.

Figure 5. Bipartite network of the IPCC contributors (grey) and the capacities in which they have served (coloured according to their functional and thematic division). The nodes representing the contributors are sized according to their bipartite bridgeness score and coloured in red if they are members of the IPCC Bureau and in grey if they are not. Labels are shown only for the 140 contributors whose bridgeness is higher than 1300.

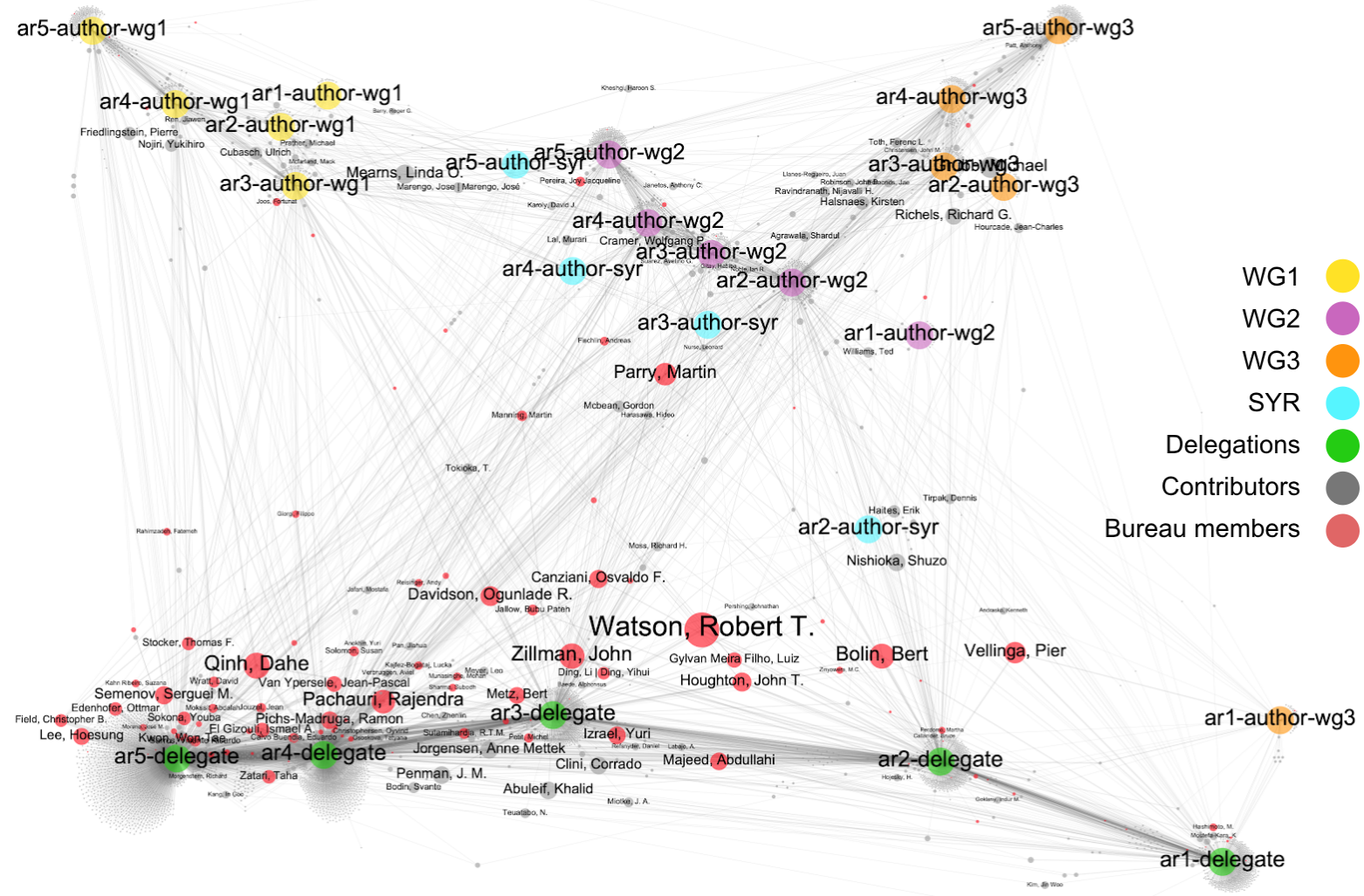

Looking at figure 5 above, it is easy to observe that the contributors with the highest bridgeness are positioned in the bottom of the figure. This indicates that the most important bridges tend to be also delegates. The bridges that are also members of the IPCC Bureau (the red nodes) are positioned particularly close to delegate capacities. This captures an old tradition of the IPCC: in the first assessment reports, most members of the Bureau were also head of their national delegation. In the latest ARs, this is no longer the case, but the members of the Bureau are still supposed to represent their countries (as well as the geographical regions of their countries) and are often listed among the members of their national delegations in official documents (and hence in our database). It is also interesting to note that the five scientists that have so far served as Chair of the IPCC (Bert Bolin, Robert Watson, Rajendra Pachauri and Hoesung Lee) are all very visible as bridges and positioned close to the ARs that they chaired.

A closer examination of figure 5 also reveals that the bridges tend to be positioned toward the left, suggesting that more bridging is performed in the later assessment cycles than in the earlier. This is, to some extent, a simple effect of the increase in the size of the IPCC, but it also derives from the effort of the organisation to encourage its contributors to serve in different capacities and connect its different divisions. A way to test this idea is to count the number of functional and thematic bridges active in the different assessment cycles (Table 4) ${ }^{11}$. In Table 4, darker cell colours indicate higher

\footnotetext{
${ }^{11}$ To be precise, since the same person can serve as two different types of bridges during the same AR, table 4 indicates the number of "bridging actions" rather than the number of individual bridges.
} 
numbers, and this makes it easy to observe the general increase in the number of bridging actions (both in functional and thematic bridging) in successive assessment reports - though with an interesting reduction in functional bridging between AR4 and AR5 and in thematic bridging between AR3 and AR4.

Table 4. Number of functional and thematic bridging actions between different capacities over the five assessment cycles (darker background indicates higher numbers).

\begin{tabular}{|l|c|c|c|c|c|}
\hline & AR1 & AR2 & AR3 & AR4 & AR5 \\
\hline Delegations-SYR & 0 & 20 & 13 & 12 & 15 \\
\hline Delegations-WG1 & 5 & 10 & 19 & 31 & 22 \\
\hline Delegations-WG2 & 4 & 38 & 36 & 28 & 29 \\
\hline Delegations-WG3 & 20 & 10 & 17 & 39 & 20 \\
\hline All functional & $\mathbf{2 9}$ & $\mathbf{7 8}$ & $\mathbf{8 5}$ & $\mathbf{1 1 0}$ & 13 \\
\hline SYR-WG1 & 0 & 6 & 11 & 13 & 18 \\
\hline SYR-WG2 & 0 & 9 & 12 & 13 & 15 \\
\hline SYR-WG3 & 0 & 6 & 12 & 11 & 5 \\
\hline WG1-WG2 & 0 & 2 & 10 & 3 & 0 \\
\hline WG1-WG3 & 0 & 1 & 2 & 0 & 3 \\
\hline WG2-WG3 & $\mathbf{3}$ & 4 & 9 & $\mathbf{8}$ & $\mathbf{5 4}$ \\
\hline All thematic & $\mathbf{3}$ & $\mathbf{2 8}$ & $\mathbf{5 6}$ & $\mathbf{1 5 3}$ & $\mathbf{1 4}$ \\
\hline Functional+Thematic & $\mathbf{3 2}$ & $\mathbf{1 0 6}$ & $\mathbf{1 4 1}$ & \\
\hline
\end{tabular}

Figure 6 illustrates the number of temporal bridging actions between different ARs, with the increasing thickness of arcs connecting pairs of ARs from left to right indicating an increase in bridging with time.

Figure 6. Bridging actions between different ARs.

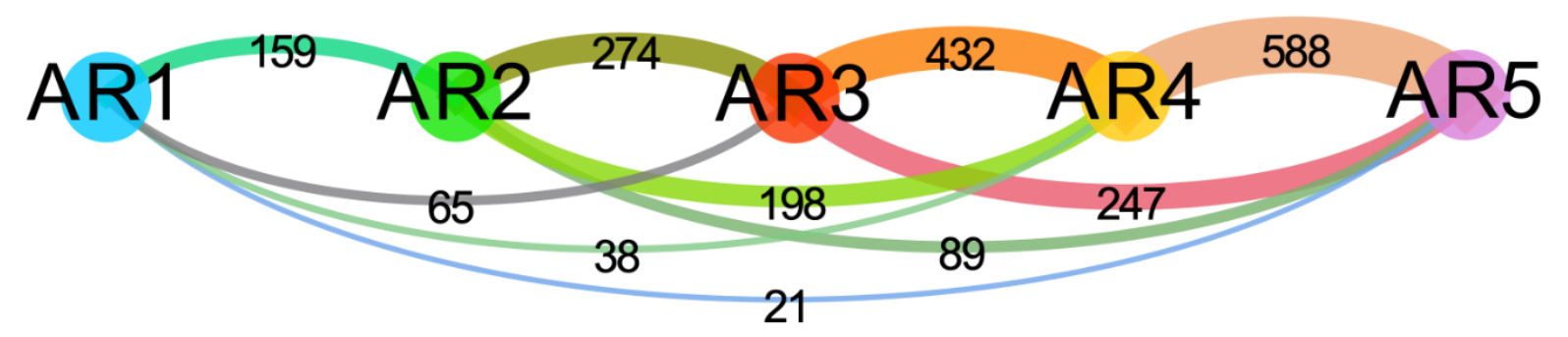

Since our dataset contains information on not only in which IPCC capacities different individuals have participated in but also their country of affiliation during each participation ${ }^{12}$, we can aggregate the values of bridgeness by country and country groups. Table 5 shows the number of individual bridges and the sum of their bridgeness for different countries of different development status and regions (according to the official classification of the World Meteorological Organisation used in the IPCC). It is important to note that, in order to avoid double counting, we excluded from the sums of table 5 , all individuals who were affiliated to different countries in different assessment reports.

\footnotetext{
12 The country of affiliation does not necessarily correspond to the nationality of individuals but indicated instead the nationality of their institution or the country that they were representing.
} 
Table 5. Sum of bridgeness, number of bridges and number of contributors by development status and World Meteorological Organisation geographical regions.

\begin{tabular}{|l|c|c|c|}
\hline Country groupings & Bridgeness Sum & Bridges No. & Contributors No. \\
\hline Developed Countries & 30.5154 & 591 & 2.444 \\
\hline Developing Countries & 20.7877 & 507 & 2.828 \\
\hline Economies in Transition & 21.102 & 50 & 278 \\
\hline Region I (Africa) & 51.030 & 157 & 806 \\
\hline Region II (Asia) & 115.656 & 253 & 1.430 \\
\hline Region III (Sud America) & 31.080 & 67 & 361 \\
\hline Region IV (Nord and Central America) & 99.745 & 202 & 924 \\
\hline Region V (Sud-West Pacific) & 33.627 & 75 & 398 \\
\hline Region VI (Europe) & 186.860 & 361 & 1.575 \\
\hline
\end{tabular}

Table 5 shows that, despite having a smaller number of total contributors, developed countries have more bridges and a much larger sum of bridgeness compared with developing countries. This confirms the dominance of developed countries in the IPCC and in climate science in general (Corbera et al., 2015). Similarly, when looking at regions, we can observe a clear dominance of Europe (both for number of bridges and sum of bridgeness) followed by Asia and North and Central America. The very good result of Asia is confirmed by the fact the current Chair of the IPCC (Hoesung Lee) is a scientist from South Korea and the previous one (Rajendra Pachauri) from India.

Aggregating the same information by country (table 6 and figure 7) reveals an extremely skewed distribution of bridgeness in the IPCC. While such unevenness is to a large extent a simple consequence of the unequal number of IPCC contributors by country, the skewness is considerably higher for the bridgeness (the top-10 countries for bridgeness control more of this variable than all the other countries together, compared to the top-14 for number of bridges and top-19 for number of contributors). This suggests that the dominance of some countries in the IPCC may be even greater than may appear by looking just at the number of contributors, as these countries seem to control most of the key bridging positions in the organisation.

Table 6. Total bridgeness, number of bridges and number of contributors for the 20 countries with the highest total bridgeness.

\begin{tabular}{|l|c|c|c|c|}
\hline Countries & $\begin{array}{c}\text { Bridgeness } \\
\text { Sum }\end{array}$ & $\begin{array}{c}\text { Bridges } \\
\text { No. }\end{array}$ & $\begin{array}{c}\text { Contributors } \\
\text { No. }\end{array}$ \\
\hline USA & 65820 & 109 & 499 \\
\hline UK & 32095 & 47 & 175 \\
\hline China & 31180 & 66 & 219 \\
\hline Japan & 22077 & 53 & 317 \\
\hline Australia & 19275 & 33 & 116 \\
\hline Germany & 17524 & 35 & 178 \\
\hline Netherlands & 17267 & 35 & 87 \\
\hline India & 15856 & 23 & 99 \\
\hline Canada & 14821 & 39 & 141 \\
\hline South Korea & 11985 & 21 & 203 \\
\hline France & 11860 & 26 & 115 \\
\hline Brazil & 11836 & 19 & 102 \\
\hline Saudi Arabia & 10995 & 20 & 113 \\
\hline Argentina & 10479 & 13 & 57 \\
\hline Denmark & 10299 & 11 & 45 \\
\hline Sweden & 9852 & 11 & 50 \\
\hline Cuba & 9066 & 8 & 18 \\
\hline Russian Fed. & 8739 & 12 & 50 \\
\hline Switzerland & 8725 & 10 & 50 \\
\hline Italy & 7458 & 11 & 52 \\
\hline
\end{tabular}

Figure 7. Bar chart of the total bridgeness for all the countries participating to the IPCC. 


\section{Conclusion}

In this paper, we investigated the relational architecture of a particularly influential organization in the international climate regime: the Intergovernmental Panel on Climate Change (IPCC). The IPCC is an interesting case study not only for its crucial role of "trading zone" (Collins et al., 2007) between the sciences of climate change and national and international policymaking, but also for its capacity to survive and prosper for more than thirty years despite its relatively light institutional structures. The IPCC produces its expert assessments, drawing on the voluntary contributions of a multitude of participants who maintain their primary affiliation to other institutions and are, in most cases, replaced at every new assessment cycle.

Besides its institutional practices and bureaucratic procedures, the IPCC owes its continuity and persistence to the individuals that remained in the organisation for several assessments, or that served in more than one of its working groups, or who contributed to its operations simultaneously as scientific experts and as national delegates. These bridge individuals play a crucial role in the IPCC stabilizing its complex architecture and gluing together it's different (and otherwise quite independent subparts).

To identify these bridge individuals, we proposed a new measure of bipartite bridgeness defined at the as the summation of the inverse Jaccard similarity coefficient of the neighbourhoods of all pairs of neighbours of a given node. As we illustrated using a database of the eight thousand individuals who contributed to the IPCC since its foundation, this measure of bipartite bridgeness is more informative than the simple degree, as it takes into account the importance and the rareness of the connections assured by each bridge. Using this measure, we investigated the IPCC as a network-organisation and inspected the individuals the temporal, thematic and functional bridging of its divisions. Besides the IPCC, our measure and the protocol that we employed to investigate bipartite bridges can, we believe, be fruitfully applied to other complex organisations that can be represented as bipartite networks of contributors and subparts.

\section{References}

Allen, Michael Patrick. 1974. "Interlocking Corporate Directorates." American Sociological Review 39(3): 393406.

Boltanski, Luc. 1973. "L’espace Positionnel : Multiplicité Des Positions Institutionnelles et Habitus de Classe." Revue française de sociologie 14(1): 3-26.

Borgatti, Stephen P., and Martin G. Everett. 1997. "Network Analysis of 2-Mode Data.” Social Networks 19: 243-69.

Brandes, Ulrik. 2001. “A Faster Algorithm for Betweenness Centrality.” Journal of Mathematical Sociology 25(2): $163-77$.

Burt, Ronald S. 2005. Brokerage \& Closure: An Introduction to Social Capital. Oxford: University Press.

Burt, Ronald S., Martin Kilduff, and Stefano Tasselli. 2013. "Social Network Analysis: Foundations and Frontiers on Advantage." Annual Review of Psychology 64(1): 527-47. http://www.annualreviews.org/doi/10.1146/annurev-psych-113011-143828.

Collins, Harry, Robert Evans, and Mike Gorman. 2007. "Trading Zones and Interactional Expertise." Studies in History and Philosophy of Science Part A 38(4): 657-66. https://linkinghub.elsevier.com/retrieve/pii/S003936810700060X.

Corbera, Esteve, Laura Calvet-Mir, Hannah Hughes, and Matthew Paterson. 2015. "Patterns of Authorship in the IPCC Working Group III Report.” Nature Climate Change 6(September): 1-7. http://www.nature.com/doifinder/10.1038/nclimate2782. 
De Pryck, Kari. 2021. "Intergovernmental Expert Consensus in the Making. The Case of the Summary for Policymakers of the IPCC 2014 Synthesis Report." Global Environmental Politics (Forthcoming).

Durkheim, Emile. 1884. "Règles de La Méthode Sociologique." http://classiques.uqac.ca/classiques/Durkheim_emile/regles_methode/durkheim_regles_methode.pdf.

Durkheim, Emile. 1982. The Rules of Sociological Method (Translation by W.D. Hall, Edited by Steven Lukes). New York: The Free Press.

Emirbayer, Mustafa. 1997. "Manifesto for a Relational Sociology." American Journal of Sociology 103(2): 281317.

Euler, Leonhard. 1736. "Solutio Problematis Ad Geometriam Situs Pertinentis." Commentarii academiae scientiarum petropolitanae (8): 128-140.

Freeman, L.C. 1977. "A Set of Measures of Centrality Based on Betweenness Author ( s ): Linton C . Freeman Published by : American Sociological Association Stable URL : Http://Www.Jstor.Org/Stable/3033543 Accessed : 18-04-2016 12:00 UTC Your Use of the JSTOR Archive Indicat.” Sociometry 40(1): 35-41.

Freeman, Linton C. 2004. The Development of Soical Network Analysis. Vancouver: Empirical Press.

Granovetter, Mark. 1973. “The Strength of Weak Ties.” American Journal of Sociology 78(6): 1360-80.

Hughes, Hannah. 2015. "Bourdieu and the IPCC's Symbolic Power.” Global Environmental Politics 15(4): 85104. http://www.mitpressjournals.org/doi/10.1162/GLEP_a_00323.

Jacomy, Mathieu, Tommaso Venturini, Sebastien Heymann, and Mathieu Bastian. 2014. "ForceAtlas2, a Continuous Graph Layout Algorithm for Handy Network Visualization Designed for the Gephi Software.” PloS one 9(6): e98679. http://www.ncbi.nlm.nih.gov/pubmed/24914678 (June 17, 2014).

Jean-Loup Guillaume, Matthieu Latapy. 2004. "Bipartite Structure of All Complex Networks.” Information Processing Letters 90(5): 215-21. http://linkinghub.elsevier.com/retrieve/pii/S0020019004000754 (August 30, 2011).

Latour, Bruno. 2005. Reassembling the Social. An Introduction to Actor-Network-Theory. Oxford University Press.

Lidskog, Rolf, and Göran Sundqvist. 2015. "When Does Science Matter? International Relations Meets Science and Technology Studies.” Global Environmental Politics 15(1): 1-20. http://www.mitpressjournals.org/doi/10.1162/GLEP_a_00269.

Moreno, Jacob. 1934. Who Shall Survive? Washington, DC: Nervous and Mental Disease Publishing.

Reinalda, Bob, and Bertjan Verbeek, eds. 1998. Autonomous Policy Making By International Organisations. New York: Taylor \& Francis.

Scott, John. 1991. Social Network Analysis. Los Angeles: Sage.

Tarde, Gabriel. 1893. Monadologie et Sociologie. Paris: Les empêcheurs de penser en rond. http://classiques.uqac.ca/classiques/tarde_gabriel/monadologie/Monadologie_et_socio.pdf (October 2, 2010).

Tora, Skodvin. 2000. Structure and Agent in the Scientific Diplomacy of Climate Change. Dordrecht: Kluwer Academic Publishers.

Venturini, Tommaso, Mathieu Jacomy, Audrey Baneyx, and Paul Girard. 2016. "Hors Champs: La Multipositionnalité Par l'analyse Des Réseaux.” Réseaux 199(5): 11-42. http://www.medialab.sciencespo.fr/publications/hors-champs-la-multipositionnalite-par-lanalyse-des-reseaux/.

Venturini, Tommaso, Mathieu Jacomy, and Pablo Jensen. 2020. Social Science Research Network What Do We See When We Look at Networks an Introduction to Visual Network Analysis and Force-Directed Layouts. https://papers.ssrn.com/sol3/papers.cfm?abstract_id=3378438.

Venturini, Tommaso et al. 2014. "Climaps by Emaps in 2 Pages (A Summary for Policy Makers and Busy People in General)." Social Science Research Network (ID 2532946).

http://papers.ssrn.com/abstract=2532946 (February 18, 2015).

White, Harrison C. 1992. "Identity and Control. A Structural Theory of Social Action." 